\title{
Applying a Prediction Model for Vaginal Birth after Cesarean to a Latina Inner-City Population
}

\author{
Michelle T. Nguyen, MD ${ }^{1}$ (1) Teodocia Maria Hayes-Bautista, $\mathrm{PhD}^{2}$ Paul Hsu, $\mathrm{PhD}^{3}$ \\ Christina Bragg, MHA ${ }^{1}$ Irving Chopin, BS ${ }^{4}$ Kathryn J. Shaw, MD ${ }^{5}$ \\ ${ }^{1}$ Department of Obstetrics and Gynecology, Adventist Health White \\ Memorial Medical Center, Los Angeles, California \\ 2 Department of Graduate Medical Education, Adventist Health White \\ Memorial Medical Center, Los Angeles, California \\ ${ }^{3}$ Department of Epidemiology, UCLA School of Public Health, Los \\ Angeles, California \\ ${ }^{4}$ Department of Organizational Performance, Adventist Health White \\ Memorial Medical Center, Los Angeles, California \\ ${ }^{5}$ Department of Maternal-Fetal Medicine, Adventist Health White \\ Memorial Medical Center, Los Angeles, California \\ Address for correspondence Michelle Tu Anh Nguyen, MD, Adventist \\ Health White Memorial Medical Center, Medical Education - OB/GYN, \\ 1720 Cesar E. Chavez Avenue, Los Angeles, CA 90033 \\ (e-mail: nguyenmt02@ah.org). \\ Am J Perinatol Rep 2020;10:e148-e154.
}

\begin{abstract}
Keywords

- trial of labor after cesarean

- vaginal birth after cesarean

- hispanic

- Latina

- ethnicity

Background The Maternal-Fetal Medicine Units (MFMU) Network developed a prediction model for calculating the likelihood of successful vaginal birth after cesarean (VBAC) in patients undergoing a trial of labor after cesarean (TOLAC). In this prediction model, Latina ethnicity is considered a negative predictive factor for successful VBAC. Subsequent studies have found mixed results regarding VBAC success in Latina ethnicity.

Objective Our aim was to compare the predicted chance of successful VBAC (as calculated using the MFMU prediction model) to actual TOLAC outcomes in a large Latina sample.

Study Design We performed a retrospective cohort study of Latinas who underwent TOLAC at our institution from January 1, 2013 to December 31, 2016. The MFMU prediction model was used to calculate each participant's predicted success, and the participants were then categorized into three groups based on predicted success: low $(<35 \%)$, moderate $(35-65 \%)$, and high $(>65 \%)$. The predicted success rates versus actual outcomes were compared among the three groups.

Results A total of 567 Latinas met inclusion criteria. Successful VBAC occurred in 476 patients (84\%). VBAC was achieved in $65.3 \%$ of the low predicted success group, $84.4 \%$ of the moderate predicted success group, and $91.7 \%$ of the predicted high success group. Actual VBAC success rates exceeded the predicted success rates for the low and moderate groups.

Conclusion Our results question whether Latina ethnicity should continue to be considered a negative predictive factor for VBAC success. Our results also suggest that Latinas with a low predicted VBAC success should not necessarily be discouraged from attempting TOLAC.
\end{abstract}

received

October 3, 2019

accepted

January 19, 2020
DOI https://doi.org/

$10.1055 / \mathrm{s}-0040-1708493$. ISSN 2157-6998.
Copyright $\odot 2020$ by Thieme Medical

Publishers, Inc., 333 Seventh Avenue, New York, NY 10001, USA Tel: +1(212) 760-0888.
License terms

ㄷ) (i) $\ominus$ (\$) 
The rate of cesarean delivery in the United States has increased from $5 \%$ in 1970 to $31.9 \%$ in $2016 .{ }^{1}$ Offering a trial of labor after cesarean section (TOLAC) is one strategy to help reduce the rate of cesarean delivery. However, the overall morbidity and mortality associated with cesarean delivery in the setting of failed TOLAC is higher than the overall morbidity and mortality associated with elective repeat cesarean delivery.

Different tools have been developed to help obstetricians predict the chances of successful vaginal birth after cesarean (VBAC) and to facilitate shared decision-making with patients regarding TOLAC versus elective repeat cesarean delivery. One of the most widely recognized prediction models is the VBAC calculator developed in 2007 by the National Institute of Child Health and Human Development. Maternal-Fetal Medicine Units Network (MFMU) based on observational data published in 2005. 2,3 This prediction model was subsequently expanded in 2009 to include additional information available at the time of admission. ${ }^{4}$ Both the original 2007 prediction model and the expanded 2009 prediction model identified "Hispanic" or "Latina" ethnicity as a negative predictive factor, based on an $n=2,362$ Latinas ( $19.9 \%$ of the MFMU study population). In 2006 Hollard et al came to a similar conclusion that Latinas are significantly less likely than Caucasian women to achieve successful VBAC, based on a study that included $n=993$ Latinas ( $39 \%$ of the study population). ${ }^{5}$

More recently in 2017, Maykin et al. performed a retrospective cohort study on an ethnically diverse population in which Latinas outnumbered any other ethnic group $(n=229$ Latinas, $40.3 \%$ of the study population). ${ }^{6}$ This study categorized patients into one of three groups based on the percent chance of VBAC success: "low" if their predicted success was $<35 \%$, "moderate" if their predicted success was 35 to $65 \%$, and "high" if their predicted success $>65 \%$. The majority of Latinas in the study fell into the low $(<35 \%)$ predicted success group. In contrast to prior studies, Maykin et al. observed that the MFMU prediction model underestimated the likelihood of VBAC success for patients in the low $(<35 \%)$ predicted success group and concluded that ethnicity is not predictive of VBAC success.

A recent commentary in Obstetrics \& Gynecology regarding disparities in women's health suggests that race has been "historically mishandled" in research and clinical care due to the presumption that race alone implies a biologic difference. ${ }^{7}$ We suspected that for our study population residing in East Los Angeles, there may be similar complexities in using "Latina" ethnicity as an a priori negative factor for predicting VBAC success. The objective of our study was to compare predicted VBAC success rates according to the MFMU prediction model with the observed VBAC success rates in an exclusively Latina patient population.

\section{Materials and Methods}

The western Institutional Review Board approved this study which was conducted at Adventist Health White Memorial (AHWM). AHWM is a teaching hospital in inner-city Los Angeles with a predominantly Latina patient population. A total of 15,245 deliveries occurred at AHWM from January 1, 2013 to December 31, 2016. All 701 women who attempted
TOLAC at AHWM within this time frame were identified through a review of the Obstetrics/Gynecology Department's archive of statistical data forms for each delivery. Each patient's ethnicity was based on self-reported information at the time of admission. 95\% of our TOLAC patients during the study period were Latina; only $5 \%$ of all TOLAC patients identified themselves as Caucasian, African American, Asian, or other ethnicity and were excluded from analysis. The following Latina TOLAC patients were also excluded: $<18$ years of age, preterm ( $<37$ weeks of gestational age), fetal demise, lethal fetal anomalies, deliveries at home or in transit to the hospital, precipitous deliveries upon arrival or shortly thereafter, incomplete medical records, and laboring patients who requested to stop TOLAC and proceed with elective repeat cesarean delivery. - Fig. 1 depicts a flow diagram of the final study population after exclusions were made. Patients with two prior cesarean deliveries were not excluded because the prediction model has been validated by Metz et al. (2015) for women with two prior cesarean sections. ${ }^{8}$

To calculate the chance of successful VBAC for each patient using the MFMU prediction model, the following patient characteristics on admission were obtained from medical records: age, height, weight, body mass index (BMI), ethnicity, any prior vaginal delivery, any prior VBAC, indication for prior cesarean delivery, estimated gestational age at delivery, dilation, effacement, station, whether the patient had hypertensive disease of pregnancy, and whether labor was induced or spontaneous. A comparison of our study cohort characteristics to the 2007 MFMU cohort characteristics is described in - Table 1.

We extracted the following data from the medical records for each patient: maternal comorbidities prior to labor onset (chronic hypertension and pregestational and gestational diabetes), intrapartum information (augmentation of labor with oxytocin, epidural use, and administration of magnesium sulfate), neonatal information (gestational age at delivery, birth weight, and 5minute Apgar's score), and peripartum complications (gestational hypertension and preeclampsia, chorioamnionitis, endometritis, uterine rupture, postpartum hemorrhage, and cesarean hysterectomy). In our study, uterine rupture is defined as a complete separation of the scar seen intraoperatively, with clinical signs and symptoms suspicious for rupture prior to surgery. Postpartum hemorrhage is defined as blood loss $\geq 500$ ccs for vaginal delivery or $\geq 1,000$ ccs for cesarean delivery.

The MFMU prediction model was used to calculate each patient's probability of VBAC success. As in the study by Maykin et al., our study participants were assigned to one of three groups based on the percent chance of VBAC success: "low" if their predicted success was $<35 \%$, "moderate" if their predicted success was 35 to $65 \%$, and "high" if their predicted success $>65 \%$.

All statistical analyses and testing were performed using SAS software. For continuous variables such as maternal age or BMI, $p$-values were generated through analyses of variance. Values for categorical variables were calculated with the Chi-square statistic; when approximately $50 \%$ of the cells had expected counts of less than 5, the Chi-square was replaced with Fisher's exact test (two-sided). When too many cells had expected counts of less than 5 , statistical 

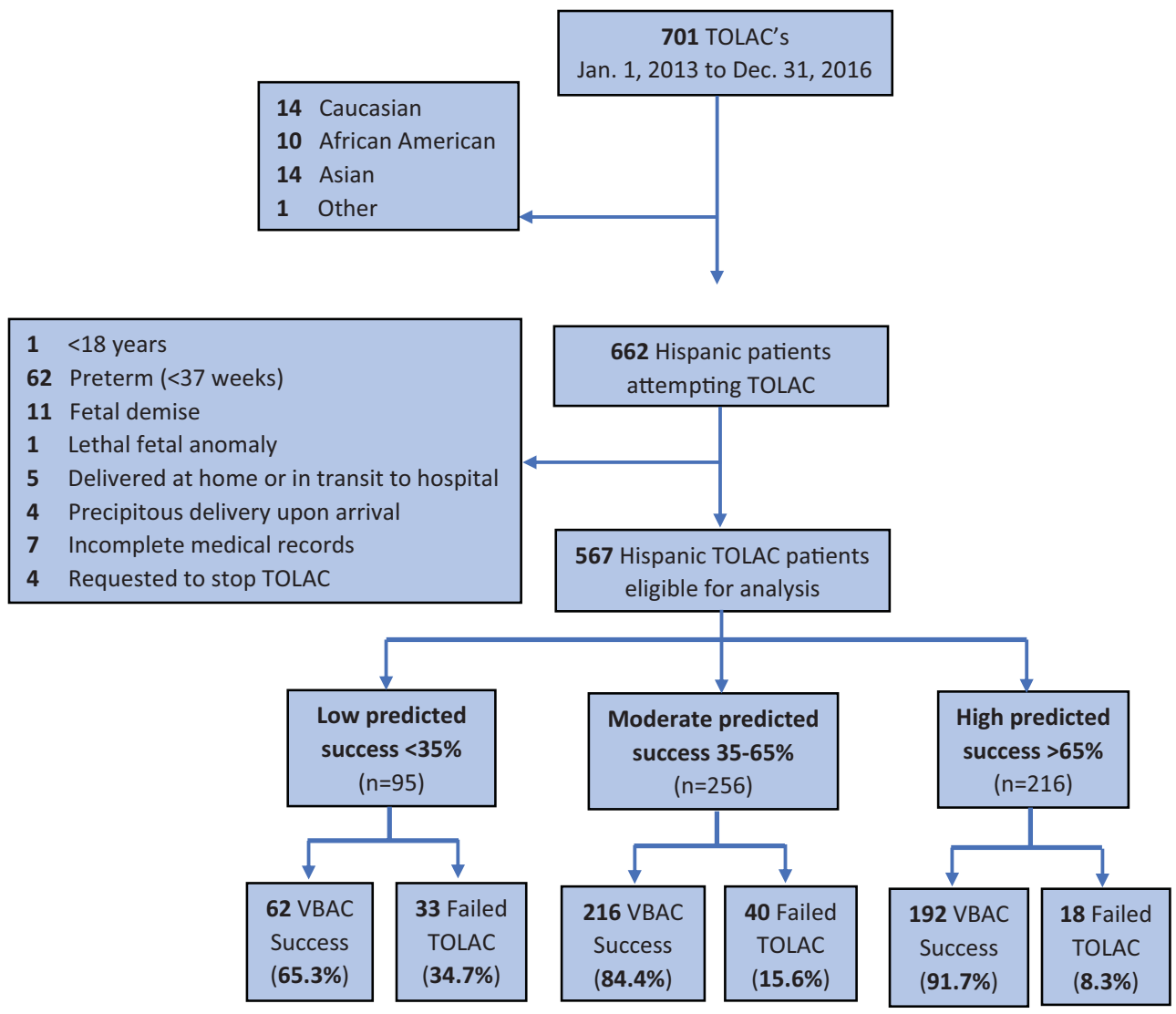

Fig. 1 Flow chart of study participants, exclusions, and final classification based on predicted success. TOLAC, trial of labor after cesarean; VBAC, vaginal birth after cesarean.

testing was not performed and $p$-values were not noted in the tables. For all other variables, we presented the actual calculated $p$-value, with a lower bound of 0.001 (any lower values were represented as $<0.001$ ).

\section{Results}

Of the 701 women who attempted TOLAC at AHWM during the study period, 662 were Latina and 567 of these Latina

Table 1 A Comparison of the 2007 maternal-fetal medicine units cohort to the current study cohort

\begin{tabular}{|l|l|l|}
\hline Variable & $\begin{array}{l}\text { 2007 MFMU } \\
\text { cohort }\end{array}$ & $\begin{array}{l}\text { Current study } \\
\text { cohort }\end{array}$ \\
\hline Average maternal age (y) & $28.6 \pm 5.8$ & $29.3 \pm 5.6$ \\
\hline Average BMI $\left(\mathrm{kg} / \mathrm{m}^{2}\right)$ & $26.4 \pm 6.3$ & $33.7 \pm 6.1$ \\
\hline $\begin{array}{l}\text { Prior cesarean delivery } \\
\text { for arrest of dilation or } \\
\text { arrest of descent }\end{array}$ & $4,108(36.3 \%)$ & $224(39.5 \%)$ \\
\hline Any prior vaginal delivery & $5,617(47.5 \%)$ & $262(46.2 \%)$ \\
\hline $\begin{array}{l}\text { Vaginal delivery after } \\
\text { prior cesarean }\end{array}$ & $3,996(33.7 \%)$ & $164(28.9 \%)$ \\
\hline Pre-existing diabetes & $99(0.84 \%)$ & $12(2.1 \%)$ \\
\hline Latinas & $2,362(19.9 \%)$ & $567(100 \%)$ \\
\hline
\end{tabular}

Abbreviation: BMI, body mass index; MFMU, maternal-fetal medicine units.
TOLAC patients were eligible for analysis (-Fig. 1). Within the total cohort of 567 Latinas undergoing TOLAC, 476 (84.0\%) successfully achieved VBAC and 91 (16.0\%) failed TOLAC.

A comparison of variables between the 476 patients who achieved VBAC and the 91 patients who failed TOLAC is summarized in - Table 2 . The successful VBAC group and the failed TOLAC group were similar in terms of rates of advanced maternal age, hypertensive disease, epidural use, and intrapartum magnesium use. However, Latina patients who failed TOLAC were more likely to have the following characteristics: obesity, diabetes, prior cesarean delivery for arrest of dilation or descent, and induced labor. Latinas who failed TOLAC were also more likely to experience chorioamnionitis. There were not enough cases of endometritis or 5-minute Apgar's score $<7$ to make statistically meaningful comparisons between the two groups. Overall, the majority of negative predictive factors in the MFMU prediction model (i.e., obesity, prior cesarean delivery for arrest of dilation or descent, and induced labor) were also relevant in our Latina patient population.

The individual predicted VBAC success rates for our Latina TOLAC patients ranged from 5.0 to $94.0 \%$ ( - Fig. 1 and -Tables 3-5). The 95 patients in the "low" (<35\%) predicted success group had an actual VBAC success rate of $65.3 \%$. The 256 patients in the "moderate" (35-65\%) predicted success group had an actual VBAC success rate of $84.4 \%$. The 216 patients in the "high" (>65\%) predicted success group had an 
Table 2 Characteristics of successful vaginal birth after cesarean group compared with characteristics of failed trial of labor after cesarean group

\begin{tabular}{|c|c|c|c|c|c|c|c|}
\hline & $\begin{array}{l}\text { VBAC } \\
(n=476)\end{array}$ & & $\begin{array}{l}\text { Failed TOLAC } \\
(n=91)\end{array}$ & & $\begin{array}{l}\text { Total } \\
(n=567)\end{array}$ & & $p$-Value \\
\hline Advanced maternal age ( $\geq 35$ years) & 89 & $18.70 \%$ & 10 & $10.99 \%$ & 100 & $17.46 \%$ & 0.076 \\
\hline $\mathrm{BMI} \geq 30 \mathrm{~kg} / \mathrm{m}^{2}$ & 339 & $71.22 \%$ & 76 & $83.52 \%$ & 416 & $73.19 \%$ & 0.015 \\
\hline \multicolumn{8}{|l|}{ Indication for prior cesarean } \\
\hline Arrest of dilation or descent & 175 & $36.76 \%$ & 49 & $53.85 \%$ & 224 & $39.51 \%$ & \multirow[t]{2}{*}{0.002} \\
\hline Other (e.g., nonreassuring FHT, nonvertex) & 301 & $63.24 \%$ & 42 & $46.15 \%$ & 346 & $60.49 \%$ & \\
\hline \multicolumn{8}{|l|}{ Labor type } \\
\hline Spontaneous & 402 & $84.45 \%$ & 62 & $68.13 \%$ & 466 & $81.83 \%$ & $<0.001$ \\
\hline Induction & 74 & $15.55 \%$ & 29 & $31.87 \%$ & 104 & $18.17 \%$ & $<0.001$ \\
\hline Augmentation & 212 & $44.54 \%$ & 41 & $45.05 \%$ & 255 & $44.62 \%$ & 0.928 \\
\hline \multicolumn{8}{|l|}{ Comorbidities } \\
\hline Hypertensive disease of pregnancy & 36 & $7.56 \%$ & 10 & $10.99 \%$ & 47 & $8.11 \%$ & 0.273 \\
\hline Diabetes & 48 & $10.08 \%$ & 18 & $19.78 \%$ & 66 & $11.64 \%$ & 0.008 \\
\hline \multicolumn{8}{|l|}{ Intrapartum variables } \\
\hline Cervical ripening balloon & 45 & $9.45 \%$ & 23 & $25.27 \%$ & 69 & $11.99 \%$ & $<0.001$ \\
\hline Labor epidural & 363 & $76.42 \%$ & 71 & $78.02 \%$ & 437 & $76.68 \%$ & 0.741 \\
\hline Magnesium & 20 & $4.21 \%$ & 6 & $6.59 \%$ & 27 & $4.59 \%$ & 0.286 \\
\hline \multicolumn{8}{|l|}{ Perinatal outcomes } \\
\hline Chorioamnionitis & 45 & $9.45 \%$ & 16 & $17.58 \%$ & 61 & $10.76 \%$ & 0.022 \\
\hline 5-minute Apgar's score $<7$ & 2 & $0.42 \%$ & 3 & $3.30 \%$ & 5 & $0.88 \%$ & 0.031 \\
\hline Endometritis & 1 & $0.21 \%$ & 2 & $2.20 \%$ & 3 & $0.53 \%$ & 0.069 \\
\hline Uterine rupture & 0 & $0.00 \%$ & 3 & $3.30 \%$ & 3 & $0.53 \%$ & 0.004 \\
\hline Postpartum hemorrhage & 23 & $4.83 \%$ & 1 & $1.10 \%$ & 24 & $4.23 \%$ & 0.152 \\
\hline
\end{tabular}

Abbreviations: FHT, fetal heart tracing; TOLAC, trial of labor after cesarean; VBAC, vaginal birth after cesarean.

actual VBAC success rate of $91.7 \%$. Statistically significant differences were noted when comparing the three predicted success groups in terms of demographics and obstetrical histories (-Table 3 ), intrapartum variables and comorbidities (-Table 4), and perinatal outcomes (-Table 5). The trends in these variables among the three predicted success groups were expected, given that the three groups were defined by these exact variables which are inherent in the MFMU prediction model.

Demographic information is summarized in -Table 3. Patients with a low predicted success rate were younger (28.5 years) than patients with moderate ( 28.6 years) and high (30.5 years) predicted success rates $(p<0.001)$. The low predicted success group also had a higher average BMI $\left(37.7 \mathrm{~kg} / \mathrm{m}^{2}\right)$ than the moderate $\left(33.0 \mathrm{~kg} / \mathrm{m}^{2}\right)$ and high $\left(32.9 \mathrm{~kg} / \mathrm{m}^{2}\right)$ predicted success groups $(p<0.001)$.

Obstetrical histories are summarized in - Table 3 . Women in the low predicted success group were less likely to have had a prior vaginal delivery (3.2\%) compared with women in the moderate and high predicted success groups (23.1 and $92.6 \%$, respectively; $p<0.001)$. Women in the low predicted success group were also less likely to have had a prior VBAC (0\% vs. $6.6 \%$ vs. $68.1 \% ; p<0.001$ ).
Intrapartum variables are summarized in - Table 4. Induced labor occurred more frequently in the low predicted success group (53.7\%) compared with the moderate (15.2\%) and high $(6.0 \%)$ predicted success groups $(p<0.001)$. Correspondingly, patients with a low predicted success were less likely to have spontaneous labor (46.3\%) compared with patients with a moderate $(84.8 \%)$ or high $(94.0 \%)$ predicted success $(p<0.001)$. Furthermore, patients with a low predicted success were more likely to receive epidural anesthesia $(88.4 \%)$ than those with a moderate $(83.9 \%)$ or high (63.0\%) predicted success ( $p<0.001)$.

Comorbidities are summarized in -Table 4. There were no statistically significant differences in the rates of diabetes or chronic hypertension among the three groups. In contrast, the rates of hypertensive diseases of pregnancy (i.e., gestational hypertension and preeclampsia) showed significant difference, with the low predicted success group exhibiting a higher rate of hypertensive disease (23.2\%) than the moderate (7.8\%) and high (1.9\%) predicted success groups $(p<0.001)$. The low predicted success group also had a higher rate of intrapartum magnesium use (10.5\%) than the moderate $(5.1 \%)$ and high (1.4\%) predicted success groups $(p<0.002)$. 
e152 TOLAC Predictions in Latinas Nguyen et al.

Table 3 Demographics and obstetrical history compared among the three predicted success groups

\begin{tabular}{|c|c|c|c|c|c|c|c|c|c|}
\hline Group & $\begin{array}{l}\text { Low } \\
(n=95)\end{array}$ & & $\begin{array}{l}\text { Moderate } \\
(n=256)\end{array}$ & & $\begin{array}{l}\text { High } \\
(n=216)\end{array}$ & & $\begin{array}{l}\text { Total } \\
(n=567)\end{array}$ & & $p$-Value \\
\hline Predicted success & $<35 \%$ & & $35-65 \%$ & & $>65 \%$ & & & & \\
\hline Maternal age & $28.5 \pm 4.7$ & & $28.6 \pm 5.7$ & & $30.5 \pm 5.5$ & & $29.3 \pm 5.6$ & & $<0.001$ \\
\hline BMI $\left(\mathrm{kg} / \mathrm{m}^{2}\right)$ & $37.7 \pm 7.7$ & & $33.0 \pm 5.3$ & & $32.9 \pm 5.7$ & & $33.7 \pm 6.1$ & & $<0.001$ \\
\hline Gravidity & $2.6 \pm 0.9$ & & $3.0 \pm 1.5$ & & $4.1 \pm 1.5$ & & $3.4 \pm 1.5$ & & $<0.001$ \\
\hline Parity & $1.1 \pm 0.6$ & & $1.5 \pm 1.0$ & & $2.7 \pm 1.1$ & & $1.9 \pm 1.2$ & & $<0.001$ \\
\hline $\begin{array}{l}\text { Any prior vaginal } \\
\text { delivery }\end{array}$ & 3 & $3.16 \%$ & 59 & $23.05 \%$ & 200 & $92.59 \%$ & 262 & $46.21 \%$ & $<0.001$ \\
\hline Prior VBAC & 0 & $0.00 \%$ & 17 & $6.64 \%$ & 147 & $68.06 \%$ & 164 & $28.92 \%$ & $<0.001$ \\
\hline \multicolumn{10}{|c|}{ Prior cesarean deliveries } \\
\hline 1 & 95 & $100.0 \%$ & 248 & $96.88 \%$ & 208 & $96.30 \%$ & 551 & $97.18 \%$ & 0.178 \\
\hline 2 & 0 & $0.00 \%$ & 8 & $3.13 \%$ & 8 & $3.70 \%$ & 16 & $2.82 \%$ & \\
\hline \multicolumn{10}{|l|}{ Prior incision type } \\
\hline Low transverse $\times 1$ & 42 & $44.21 \%$ & 130 & $50.78 \%$ & 70 & $32.41 \%$ & 242 & $42.68 \%$ & $<0.001$ \\
\hline Unknown $\times 1$ & 53 & $55.79 \%$ & 118 & $46.09 \%$ & 137 & $63.43 \%$ & 308 & $54.32 \%$ & \\
\hline Low transverse $\times 2$ & 0 & $0.00 \%$ & 5 & $1.95 \%$ & 4 & $1.85 \%$ & 9 & $1.59 \%$ & \\
\hline $\begin{array}{l}\text { Low transverse } x 1 \text {, } \\
\text { unknown } \times 1\end{array}$ & 0 & $0.00 \%$ & 0 & $0.00 \%$ & 2 & $0.93 \%$ & 2 & $0.35 \%$ & \\
\hline Unknown $\times 2$ & 0 & $0.00 \%$ & 3 & $1.17 \%$ & 3 & $1.39 \%$ & 6 & $1.06 \%$ & \\
\hline \multicolumn{10}{|c|}{ Indication for prior cesarean delivery } \\
\hline Arrest of dilation & 63 & $66.32 \%$ & 71 & $27.73 \%$ & 41 & $18.98 \%$ & 175 & $30.86 \%$ & $<0.001$ \\
\hline Arrest of descent & 7 & $7.37 \%$ & 30 & $11.72 \%$ & 12 & $5.56 \%$ & 49 & $8.64 \%$ & \\
\hline $\begin{array}{l}\text { Nonreassuring fetal } \\
\text { heart tracing }\end{array}$ & 11 & $11.58 \%$ & 58 & $22.66 \%$ & 44 & $20.37 \%$ & 113 & $19.93 \%$ & \\
\hline Malpresentation & 6 & $6.32 \%$ & 41 & $16.02 \%$ & 56 & $25.93 \%$ & 103 & $18.17 \%$ & \\
\hline Other & 8 & $8.42 \%$ & 56 & $21.88 \%$ & 63 & $29.17 \%$ & 127 & $22.40 \%$ & \\
\hline
\end{tabular}

Abbreviations: BMI, body mass index; VBAC, vaginal birth after cesarean.

Perinatal outcomes are summarized in - Table 5. The only statistically significant difference in outcomes was the rate of chorioamnionitis, which trended slightly higher in patients with a lower predicted success $(14.7 \%)$ or moderate predicted success (14.1\%) compared with a high (5.1\%) predicted success $(p=0.003)$.

\section{Discussion}

The most significant finding of our study was that the application of the MFMU prediction model did not predict TOLAC success in our exclusively Latina patient population. The 567 Latinas who attempted TOLAC in our study achieved an overall 4-year VBAC rate of $84.0 \%$, which exceeds the national VBAC rate of 60 to $80 \%{ }^{1}$ When we recalculated each patient's predicted VBAC success rate using non-Latina ethnicity with all other variables unchanged, 141 patients (i.e., $24.9 \%$ of the study population) who had previously fallen in the low or moderate predicted success groups were now reclassified in the high-predicted success group (-Table 6 ).

The predicted VBAC success rates for the hypothetical nonLatina counterparts of our study population in - Table 6 still underestimated actual VBAC outcomes, but to a lesser extent. Although Latina ethnicity may not have been the sole reason for the discrepancy between predicted and actual VBAC success rates, our results still raise important questions about whether Latina ethnicity has any relevance to a patient's likelihood of TOLAC success, and whether Latina ethnicity should continue to be treated as a negative predictive factor. Past research that found an association between Latina ethnicity and TOLAC failure did not elucidate an underlying physiologic or biologic explanation for this association.

Several studies including ours have demonstrated that obesity is a risk factor for failed TOLAC, ${ }^{9-12}$ and the prevalence of obesity in the United States is higher among Hispanics $(47 \%)$ than non-Hispanic whites $(37.9 \%) .{ }^{13}$ However, Latina ethnicity was determined to be a negative predictive factor independent of obesity in the original MFMU prediction model (i.e., Latina ethnicity and obesity were separate variables in the regression analysis). Therefore, obesity does not adequately explain why Latina ethnicity has emerged as a risk factor for failed TOLAC in prior studies. In fact, our Latina patients achieved a surprisingly high VBAC rate of $84.0 \%$ despite having an average BMI of $33.7 \mathrm{~kg} / \mathrm{m}^{2}$, compared with the average BMI of $26.4 \mathrm{~kg} / \mathrm{m}^{2}$ in the MFMU cohort. 
Table 4 Intrapartum variables and maternal comorbidities compared among the three predicted success groups

\begin{tabular}{|c|c|c|c|c|c|c|c|c|c|}
\hline Group & $\begin{array}{l}\text { Low } \\
(n=95)\end{array}$ & & $\begin{array}{l}\text { Moderate } \\
(n=256)\end{array}$ & & $\begin{array}{l}\text { High } \\
(n=216)\end{array}$ & & $\begin{array}{l}\text { Total } \\
(n=567)\end{array}$ & & $p$-Value \\
\hline Predicted success & $<35 \%$ & & $35-65 \%$ & & $>65 \%$ & & & & \\
\hline Spontaneous labor & 44 & $46.32 \%$ & 217 & $84.77 \%$ & 203 & $93.98 \%$ & 464 & $81.83 \%$ & $<0.001$ \\
\hline Induction & 51 & $53.68 \%$ & 39 & $15.23 \%$ & 13 & $6.02 \%$ & 103 & $18.17 \%$ & $<0.001$ \\
\hline Augmentation & 38 & $40.00 \%$ & 133 & $51.95 \%$ & 82 & $37.96 \%$ & 253 & $44.62 \%$ & 0.006 \\
\hline Labor epidural & 84 & $88.42 \%$ & 214 & $83.92 \%$ & 136 & $62.96 \%$ & 434 & $76.68 \%$ & $<0.001$ \\
\hline $\begin{array}{l}\text { Cervical ripening } \\
\text { balloon }\end{array}$ & 40 & $42.11 \%$ & 22 & $8.59 \%$ & 6 & $2.78 \%$ & 68 & $11.99 \%$ & $<0.001$ \\
\hline $\begin{array}{l}\text { Intrapartum } \\
\text { magnesium }\end{array}$ & 10 & $10.53 \%$ & 13 & $5.08 \%$ & 3 & $1.40 \%$ & 26 & $4.59 \%$ & $<0.002$ \\
\hline Diabetes & 12 & $12.63 \%$ & 30 & $11.72 \%$ & 24 & $11.11 \%$ & 66 & $11.64 \%$ & 0.927 \\
\hline A1DM & 5 & $5.26 \%$ & 17 & $6.64 \%$ & 21 & $9.72 \%$ & 43 & $7.58 \%$ & 0.370 \\
\hline A12DM & 1 & $1.05 \%$ & 7 & $2.73 \%$ & 3 & $1.39 \%$ & 11 & $1.94 \%$ & \\
\hline Class B DM & 4 & $4.21 \%$ & 6 & $2.34 \%$ & 0 & $0.00 \%$ & 10 & $1.76 \%$ & \\
\hline Class C DM & 2 & $2.11 \%$ & 0 & $0.00 \%$ & 0 & $0.00 \%$ & 2 & $0.35 \%$ & \\
\hline $\begin{array}{l}\text { Hypertensive disease of } \\
\text { pregnancy }\end{array}$ & 22 & $23.16 \%$ & 20 & $7.81 \%$ & 4 & $1.85 \%$ & 46 & $8.11 \%$ & $<0.001$ \\
\hline Chronic HTN & 1 & $1.05 \%$ & 4 & $1.56 \%$ & 1 & $0.46 \%$ & 6 & $1.06 \%$ & 0.558 \\
\hline
\end{tabular}

Abbreviations: DM, diabetes mellitus; HTN, hypertension.

Table 5 Perinatal outcomes compared among the three predicted success groups

\begin{tabular}{|c|c|c|c|c|c|c|c|c|c|}
\hline Group & $\begin{array}{l}\text { Low } \\
(n=95)\end{array}$ & & $\begin{array}{l}\text { Moderate } \\
(n=256)\end{array}$ & & $\begin{array}{l}\text { High } \\
(n=216)\end{array}$ & & $\begin{array}{l}\text { Total } \\
(n=567)\end{array}$ & & p-Value \\
\hline Predicted success & $<35 \%$ & & $35-65 \%$ & & $>65 \%$ & & & & \\
\hline VBAC & 62 & $65.26 \%$ & 216 & $84.38 \%$ & 198 & $91.67 \%$ & 476 & $83.95 \%$ & $<0.001$ \\
\hline $\begin{array}{l}\text { 5-minute Apgar's } \\
\text { score }<7\end{array}$ & 1 & $1.05 \%$ & 3 & $1.17 \%$ & 1 & $0.46 \%$ & 5 & $0.88 \%$ & 0.715 \\
\hline Birth weight $(\mathrm{g})$ & $3,490 \pm 436$ & & $3,363 \pm 438$ & & $3,382 \pm 474$ & & $3,382 \pm 474$ & & 0.052 \\
\hline Chorioamnionitis & 14 & $14.74 \%$ & 36 & $14.06 \%$ & 11 & $5.09 \%$ & 61 & $10.76 \%$ & 0.003 \\
\hline Endometritis & 1 & $1.05 \%$ & 2 & $0.78 \%$ & 0 & $0.00 \%$ & 3 & $0.53 \%$ & 0.396 \\
\hline Uterine rupture & 1 & $1.05 \%$ & 2 & $0.78 \%$ & 0 & $0.00 \%$ & 3 & $0.53 \%$ & 0.396 \\
\hline $\begin{array}{l}\text { Postpartum } \\
\text { hemorrhage }\end{array}$ & 7 & $7.37 \%$ & 10 & $3.91 \%$ & 7 & $3.24 \%$ & 24 & $4.23 \%$ & 0.235 \\
\hline
\end{tabular}

Abbreviation: VBAC, vaginal birth after cesarean.

Table 6 Vaginal birth after cesarean rates compared among the three predicted success groups based on patient's actual ethnicity versus hypothetical non-Latina ethnicity

\begin{tabular}{|c|c|c|c|c|c|c|c|c|c|}
\hline \multirow[b]{2}{*}{ VBAC in Latinas } & \multicolumn{2}{|c|}{$\begin{array}{l}\text { Low predicted } \\
\text { success } \\
(<35 \%)\end{array}$} & \multicolumn{2}{|c|}{$\begin{array}{l}\text { Moderate predicted } \\
\text { success } \\
(35-65 \%)\end{array}$} & \multicolumn{2}{|c|}{$\begin{array}{l}\text { High predicted } \\
\text { success } \\
(>65 \%)\end{array}$} & \multicolumn{2}{|l|}{ Total } & \multirow{2}{*}{$\begin{array}{c}p \text {-Value } \\
<0.001\end{array}$} \\
\hline & $n=62 / 95$ & $65.26 \%$ & $n=216 / 256$ & $84.38 \%$ & $n=198 / 216$ & $91.67 \%$ & $n=476 / 567$ & $84.04 \%$ & \\
\hline $\begin{array}{l}\text { VBAC in } \\
\text { hypothetical } \\
\text { non-Latina } \\
\text { counterparts }\end{array}$ & $n=15 / 25$ & $60.00 \%$ & $n=122 / 162$ & $75.30 \%$ & $n=339 / 380$ & $89.21 \%$ & $n=476 / 567$ & $84.04 \%$ & $<0.001$ \\
\hline
\end{tabular}

Abbreviation: VBAC, vaginal birth after cesarean. 
The primary limitation of our study was the use of selfreported information to determine each patient's ethnicity for calculating TOLAC success. As in other studies on the application of the MFMU prediction model, including the original study, no information was provided in terms of how ethnicity or race was defined or determined. The "Latinas" who served as the focus of our study represented a heterogeneous, poorly defined ethnic group. We did not have information regarding maternal birthplace, which could have helped us to compare the TOLAC success rates of Latinas born in the United Statesversus Latinas born in Mexico versus Latinas born in other countries. The Latina population in Southern California is predominantly of Mexican ancestry, and caution should be exercised in applying generalizations from our study to Latinas of Puerto Rican, Cuban, Central American, South American, or other origin. This underscores the limitations and hazards of including race or ethnicity alone as a loosely defined variable.

Another limitation is that the number of patients who initially considered TOLAC but ultimately decided to undergo elective repeat cesarean delivery is unknown, as is the case in most studies on predicting TOLAC success. There are many reasons why a patient may choose to decline TOLAC, including the obstetrician's counseling (whether biased or unbiased), the patient's predicted success according the MFMU prediction model, and the patient's own personal values, preferences, and motivations. Our results may have differed if these patients had chosen to undergo TOLAC and were included in our study.

Our study also did not include information regarding the duration of labor for each patient undergoing TOLAC; therefore, it is unknown whether specific clinical interventions or management practices contributed to our success rates. The national changes in practice patterns that have developed since the original MFMU study in 2007 could possibly explain the higher than expected VBAC rates in our study. For example, the 2014 Obstetric Care Consensus on "Safe Prevention of the Primary Cesarean Delivery" currently allows women with a cervical dilation of at least $6 \mathrm{~cm}$ to continue labor for 4 hours with ruptured membranes and adequate uterine activity, or 6 hours with inadequate uterine activity. ${ }^{14}$ Management of category II fetal heart rate tracings were also not as standardized prior to the algorithm published by Clark et al in 2013. ${ }^{15}$

Regardless of the limitations, our study has ultimately demonstrated that Latinas should not be discouraged from undergoing TOLAC solely based on a single variable within the MFMU prediction model or based on a low predicted success score. As with patients of any other ethnicity, a Latina patient's choice to undergo TOLAC versus elective repeat cesarean delivery should involve a comprehensive shared decision-making process that includes careful consideration of multiple factors.

\section{Note}

The study findings were presented in poster format at the 85th annual meeting of Pacific Coast Obstetrical and Gynecological Society, September 26-30, 2018, Coeur d'Alene, Idaho.

\section{Funding}

The authors have no sources of funding, financial interests, or other relationships to disclose.

Conflict of Interest

None declared.

\section{References}

1 Committee on Practice Bulletins-Obstetrics. Practice bulletin no. 184: vaginal birth after cesarean delivery. Obstet Gynecol 2017; 130(05):e217-e233

2 Grobman WA, Lai Y, Landon MB, et al; National Institute of Child Health and Human Development (NICHD) Maternal-Fetal Medicine Units Network (MFMU). Development of a nomogram for prediction of vaginal birth after cesarean delivery. Obstet Gynecol 2007;109(04):806-812

3 Landon MB, Leindecker S, Spong CY, et al; National Institute of Child Health and Human Development Maternal-Fetal Medicine Units Network. The MFMU cesarean registry: factors affecting the success of trial of labor after previous cesarean delivery. Am J Obstet Gynecol 2005;193(3 Pt 2):1016-1023

4 Grobman WA, Lai Y, Landon MB, et al. Does information available at admission for delivery improve prediction of vaginal birth after cesarean? Am J Perinatol 2009;26(10):693-701

5 Hollard AL, Wing DA, Chung JH, et al. Ethnic disparity in the success of vaginal birth after cesarean delivery. J Matern Fetal Neonatal Med 2006;19(08):483-487

6 Maykin MM, Mularz AJ, Lee LK, Valderramos SG. Validation of a prediction model for vaginal birth after cesarean delivery reveals unexpected success in a diverse american population. AJP Rep 2017;7(01):e31-e38

7 Ghidei L, Murray A, Singer J. Race, research, and women's health: best practice guidelines for investigators. Obstet Gynecol 2019; 133(04):815-818

8 Metz TD, Allshouse AA, Faucett AM, Grobman WA. Validation of a vaginal birth after cesarean delivery prediction model in women with two prior cesarean deliveries. Obstet Gynecol 2015;125(04): 948-952

9 Hibbard JU, Gilbert S, Landon MB, et al; National Institute of Child Health and Human Development Maternal-Fetal Medicine Units Network. Trial of labor or repeat cesarean delivery in women with morbid obesity and previous cesarean delivery. Obstet Gynecol 2006;108(01):125-133

10 Gunatilake RP, Smrtka MP, Harris B, et al. Predictors of failed trial of labor among women with an extremely obese body mass index. Am J Obstet Gynecol 2013;209(06):562.e1-562.e5

11 Faucett AM, Allshouse AA, Donnelly M, Metz TD. Do obese women receive the necessary interventions to achieve vaginal birth after cesarean? Am J Perinatol 2016;33(10):991-997

12 Juhasz G, Gyamfi C, Gyamfi P, Tocce K, Stone JL. Effect of body mass index and excessive weight gain on success of vaginal birth after cesarean delivery. Obstet Gynecol 2005;106(04): 741-746

13 The Centers for Disease Control and Prevention's National Center for Health Statistics. Natality. Available at: ftp://ftp.cdc.gov/pub/ Health_Statistics/NCHS/Dataset_Documentation/DVS/natality/ UserGuide2015.pdf. Accessed May, 2017

14 Caughey AB, Cahill AG, Guise JM, Rouse DJ; American College of Obstetricians and Gynecologists (College); Society for MaternalFetal Medicine. Safe prevention of the primary cesarean delivery. Am J Obstet Gynecol 2014;210(03):179-193

15 Clark SL, Nageotte MP, Garite TJ, et al. Intrapartum management of category II fetal heart rate tracings: towards standardization of care. Am J Obstet Gynecol 2013;209(02):89-97 